\title{
Experimental research on fracture behavior of concrete after high temperature
}

\author{
Peng Qiu \\ College of Architecture and Civil Engineering, Jiangsu City Vocational College Nantong Campus, Nantong, 226006, China \\ qiupengr@@163.com
}

\begin{abstract}
High-strength concrete has been widely used in various complex buildings. The fracture and mechanical properties of high-strength concrete after fire have great research value. Based on the double $\mathrm{K}$ fracture model, the fracture properties of $\mathrm{C} 70$ strength grade concrete after being processed by high temperature of $25{ }^{\circ} \mathrm{C} \sim 800{ }^{\circ} \mathrm{C}$ were studied by three-point bending beam test. The change rules of fracture toughness KIC and fracture energy under different temperatures after being processed by high temperature were analyzed. The results showed that the initial crack toughness and instability toughness of $\mathrm{C} 70$ concrete decreased with the increase of temperature; the fracture energy first decreased rapidly and then decreased slowly with the development of temperature.
\end{abstract}

KEYwORDS. High temperature; Concrete; Fracture toughness; Fracture energy.

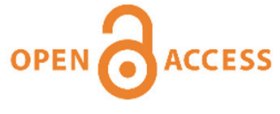

Citation: Qiu, P., Experimental research on fracture behavior of concrete after high temperature, Frattura ed Integrità Strutturale, 50 (2019) 300-309.

Received: 08.04.2019

Accepted: 21.08 .2019

Published: 01.10.2019

Copyright: (C) 2019 This is an open access article under the terms of the CC-BY 4.0, which permits unrestricted use, distribution, and reproduction in any medium, provided the original author and source are credited.

\section{INTRODUCTION}

I $\mathrm{n}$ today's construction industry, concrete as the most important engineering material has been widely used; high-rise buildings, bridges, channels will use a lot of concrete materials and there will be some small cracks in the use process of concrete. These cracks may be formed in the process of concrete forming, or may be formed by the external environment (high temperature, man-made) [1-3]. Cracks will expand in a very strong pressure state, leading to gradual increase of crack width and length and decrease of bearing capacity, which will ultimately cause the breakage of structure, and crack is one of the main factors leading to the decrease of bearing capacity of concrete structures $[4,5]$. Therefore, many researchers have concerned about the problem of concrete cracks and tried to find out why cracks generate, how cracks expand and how to prevent cracks [6]. However, the fracture mechanism of concrete is very complex as the uneven distribution of coarse aggregate and fine aggregate results in internal multi-level system. Fracture mechanics is a discipline that studies the law of crack generation and propagation in materials or structures by using elasticity and plasticity mechanics, starting from the point that macro cracks exist in materials or components. Its task is to obtain the fracture parameters of component materials and study the fracture problems of components under different external environments (high temperature, freeze thawing, external load, etc.). 
As the intrinsic characteristics of materials, scholars from all over the world have studied the fracture properties of concrete at room temperature extensively and have formulated standard test methods for mode I fracture related fracture parameters $[7,8]$. However, there are few studies on fracture properties after high temperature in China and abroad, and the research results of scholars are slightly different. A study [9] shows that the chemical composition, physical properties and mechanical properties of concrete have changed greatly at high temperature or after high temperature. In real society, besides buildings damaged by fire, there are many concrete structures affected by high temperature, such as cooling towers of power plants, prestressing nuclear reactor containers, etc. Therefore, it is of far-reaching significance to understand the high temperature fracture properties of concrete for the design, identification and strengthening of such structures. Based on the double $\mathrm{K}$ fracture toughness criterion, Yu et al. [10] carried out the experimental study on mode I fracture behavior of concrete after high temperature.

The results showed that the initial fracture toughness $K_{I C}^{Q}$ decreased gradually with the increase of temperature, while the instability toughness $K_{I C}^{S}$, fracture energy $G_{F}$ and characteristic length $l_{\mathrm{CH}}$ all showed the trend of "unchanged-risingfalling" with the increase of temperature, which indicated that the three parameters could be used as ductility indicators of concrete after high temperature. Baker [11] studied the fracture energy of concrete under different cooling regimes. The results showed that the fracture energy of concrete increases first and then decreased with the increase of test temperature, the maximum value of fracture energy appeared near $300{ }^{\circ} \mathrm{C}$, which showed that the toughness of concrete was the best at about $300{ }^{\circ} \mathrm{C}$ and the influence of different cooling regimes on fracture energy was very small. Menou et al. [12] pointed out that the value of fracture energy of concrete after high temperature was higher than that at normal temperature before reaching a certain temperature and the value of fracture energy decreased rapidly when the temperature exceeded that value. In this study, the fracture behavior of high strength concrete after high temperature processing was studied through the test of three-point bending beams with initial cracks. Comparative experiment was carried out using C70 concrete and five temperature gradients. Based on the double $\mathrm{K}$ fracture theory, the law of fracture toughness and fracture energy of high strength concrete varying with temperature was analyzed to obtain the relationship between relevant fracture parameters and temperature, so as to provide a reliable basis for damage assessment of building structures after disaster.

\section{OVERVIEW OF TEST}

he standard three-point bending beam specimens with a span-height ratio (s/h) of 4 proposed by International Union of Laboratories and Experts in Construction Materials, Systems and Structures were used in this test. A notch which was $30 \mathrm{~mm}$ deep were reserved at the middle and lower part. The basic shape of the three-point bending beam is shown in Fig. 1.

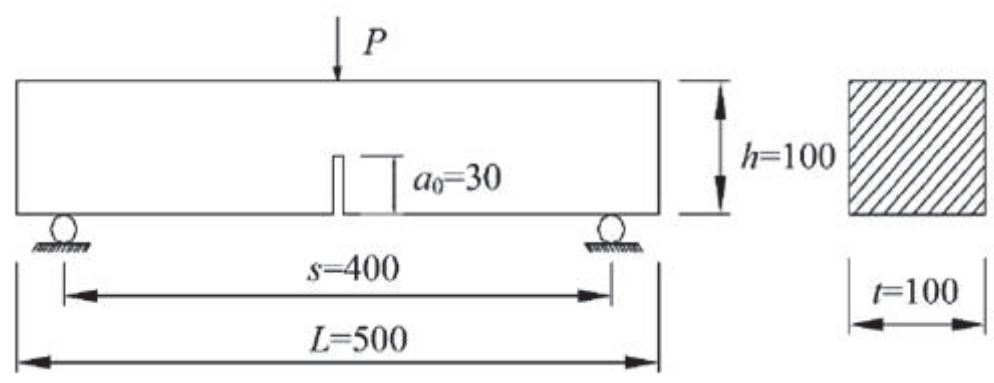

Figure 1: Schematic diagram of the three-point bending beam specimen (mm).

The highest temperature endured was $25,200,400,600$ and $800^{\circ} \mathrm{C}$ respectively. Considering the discreteness of the fracture test, five specimens were set up at each temperature, and another one was prepared for standby application. The specimen number was expressed as plain concrete strength - the maximum temperature endured, for example, 70-25 indicates that strength of the specimen was $\mathrm{C} 70$ and the maximum temperature that could endure was $25{ }^{\circ} \mathrm{C}$. The mix proportion of the concrete specimen is shown in Tab. 1. Conch PO52.5 Portland cement was used. The maximum diameter of coarse aggregate was $10 \mathrm{~mm}$, and medium sand with the diameter of $0.25-0.5 \mathrm{~mm}$ was used as the fine aggregate. After 28 days of sprinkling water curing, the compressive strength of the concrete cube reached $88.2 \mathrm{MPa}$, respectively. 


\begin{tabular}{ccccccccc}
\hline $\begin{array}{c}\text { Strength } \\
\text { grade }\end{array}$ & $\begin{array}{c}\text { Water/ } \\
\left(\mathrm{kg} \cdot \mathrm{m}^{-3}\right)\end{array}$ & $\begin{array}{c}\text { Cement } \\
/\left(\mathrm{kg} \cdot \mathrm{m}^{-3}\right)\end{array}$ & $\begin{array}{c}\text { Water } \\
\text { cement } \\
\text { ratio }\end{array}$ & $\begin{array}{c}\text { River } \\
\text { sand/ } \\
\left(\mathrm{kg} \cdot \mathrm{m}^{-3}\right)\end{array}$ & $\begin{array}{c}\text { Gravel / } \\
\left(\mathrm{kg} \cdot \mathrm{m}^{-3}\right)\end{array}$ & $\begin{array}{c}\text { Silica } \\
\text { fume/ } \\
\left(\mathrm{kg} \cdot \mathrm{m}^{-3}\right)\end{array}$ & $\begin{array}{c}\text { Water } \\
\text { reducing } \\
\text { agent } /\left(\mathrm{kg} \cdot \mathrm{m}^{-3}\right)\end{array}$ & $\begin{array}{c}\text { Unit } \\
\text { weight/ } \\
\left(\mathrm{kg} \cdot \mathrm{m}^{-3}\right)\end{array}$ \\
$\mathrm{C} 70$ & 150.00 & 441.27 & 0.31 & 615.32 & 1194.44 & 39.21 & 6.74 & 2446.97 \\
\hline
\end{tabular}

Table 1: The mixing proportion of the concrete specimen

An electric furnace with a furnace size of $500 \mathrm{~mm} \times 500 \mathrm{~mm} \times 1200 \mathrm{~mm}$ was used as the heating device, and an AI-518 (V7.1) programmed intelligent temperature regulator was used for temperature regulation and constant temperature control. The heating curve adopted the standard heating system, and the heating time was controlled according to the rate of 200 ${ }^{\circ} \mathrm{C}$ rising every half hour. When the heating temperature reached the predetermined temperature, it was switched to the constant temperature mode and kept for 3 hours. Finally, the samples were taken out after the power-off of the electric furnace and $24 \mathrm{~h}$ of natural cooling [13].

\section{Test Procedures}

WAW-1000B microprocessor-controlled electro-hydraulic servo universal testing machine was used in this test. The computer was controlled manually and the testing machine starting testing automatically. The test device is shown in Fig. 2. The test steps are as follows.

1. The support of the universal testing machine was adjusted to keep a distance of $300 \mathrm{~mm}$ between the central lines of the two supports. The screw was tightened to keep the two supports fixed. Moreover, the loading shaft was adjusted parallel to the two supports.

2. After the support was adjusted, the specimen was slowly placed between the two supports, so that the two handdrawn lines of the specimen were aligned with the center of the two supports, and the notch of the three-point bending beam was aligned with the loading axes on the testing machine.

3. The computer system was connected. The load sensor and displacement sensor of the computer were calibrated, and the bending parameters of the computer were set. Then the load, midspan displacement and notch displacement were adjusted to zero, and the initial position was adjusted.

4. The distance between the two load-bearing sheets of the electronic extensometer was adjusted to the shortest (10 $\mathrm{mm}$ ) by holding them by hand. Because of its good elasticity, the two pieces of the electronic extensometer were stuck between the two steel sheets at the crack opening. The load-opening displacement curve of the specimen was measured by the extensometer, and the load-span displacement curve was also be measured by the testing machine to obtain fracture parameters.

5. Continuous loading method was adopted in this test. The loading speed was $0.08 \mathrm{KN} / \mathrm{s}$. It was loaded directly until the specimen failed, and the control system automatically saved the data.

6. In the process of the experiment, the test machine was unloaded to prevent the oil pump from rising too high and damaging the test machine after the testing of five test specimens.

The concrete blocks which needed to be processed by $200{ }^{\circ} \mathrm{C}$ and $400{ }^{\circ} \mathrm{C}$ were directly heated to the preset temperatures. The concrete blocks which needed to be processed by $600{ }^{\circ} \mathrm{C}$ and $800{ }^{\circ} \mathrm{C}$ were pre-heated to $200{ }^{\circ} \mathrm{C}$, keeping for $24 \mathrm{~h}$, and then heated to the preset temperature from $200{ }^{\circ} \mathrm{C}$.

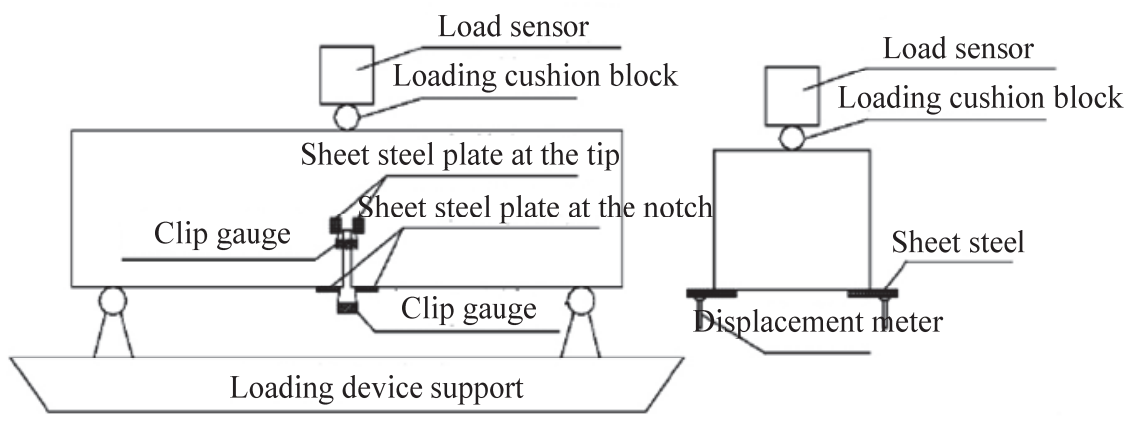

Figure 2: The testing device. 
The concrete fracture test was carried out on a $2000 \mathrm{kN}$ electro-hydraulic servo universal testing machine. The whole test process was controlled by displacement, and the loading velocity was $0.02 \mathrm{~mm} / \mathrm{min}$ to achieve stable splitting test. The average loading time of specimens which were processed with temperature lower than $400{ }^{\circ} \mathrm{C}$ was 20 minutes, while that of specimens which were processed with temperature higher than $400{ }^{\circ} \mathrm{C}$ was 40 minutes due to the long time spent in the descending section of the load-crack opening displacement curve. As shown in Fig. 2, the crack opening displacement (CMOD) and the crack tip opening displacement (CTOD) of the specimens were measured with a clamp extensometer, and the deflection of the middle position of the specimens was measured with two displacement meters.

\section{Experimental Observations}

The experimental phenomena of the three-point bending beams after high temperature processing are shown in Fig. 3. When the temperature that the concrete specimen ensured did not exceed $400{ }^{\circ} \mathrm{C}$, the crack was vertical and downward, and there was no split crack. The splitting surface was relatively flat, and there was aggregate breaking on the fracture surface. When the load has not reached its peak value, visible cracks did not appear at the tip of the specimens; but once there were visible cracks, the load of the specimens suddenly dropped and then steadily decreased. When the temperature of the concrete specimen was 600 or $800^{\circ} \mathrm{C}$, the cracks bent downward; at the beginning, several small cracks appeared on the surface of specimens, and with the increase of the load, a main crack and several split cracks appeared. With the increase of temperature, the splitting surface became more tortuous, and the phenomenon of cracks passing through aggregates decreased obviously, instead, it went around between aggregates. When the load did not reach the peak value, visible cracks appeared at the tip of the prefabricated crack; when the load reached the peak value, the crack opening became larger and the length expanded, but then they slowly decreased, and the descending section lasted longer with the increase of the temperature of the specimen. For the specimens which were processed by $400{ }^{\circ} \mathrm{C}, 600{ }^{\circ} \mathrm{C}$ and $800{ }^{\circ} \mathrm{C}$, obvious cracks detoured between the aggregate.

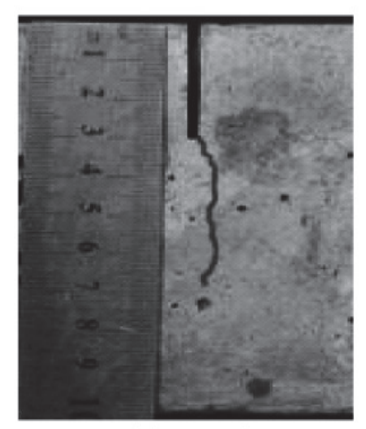

(a) $70-25$

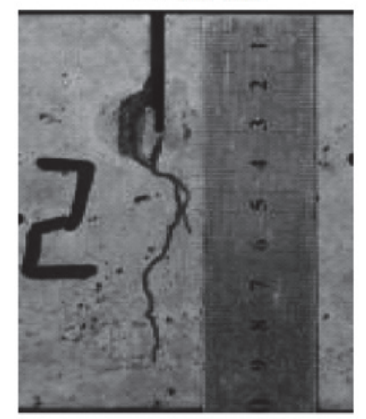

(c) $70-600$

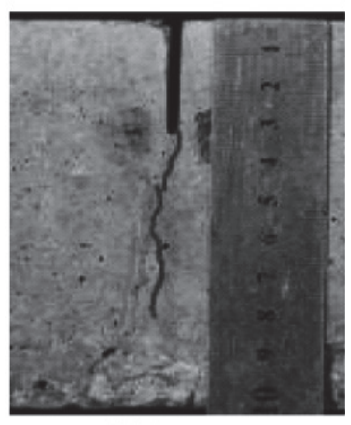

(b) $70-400$

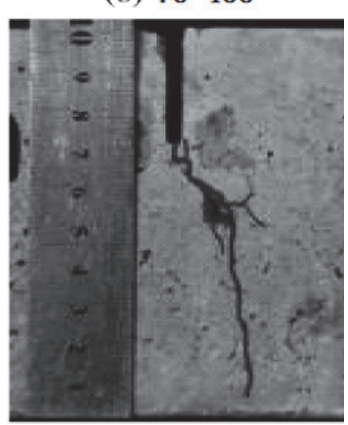

(d) $70-800$

Figure 3: The pictures of test phenomenon.

\section{TEST RESULTS AND ANALYSIS}

Measurement of ignition loss of specimens after high temperature

he loss of free water and bound water occurred in the concrete specimens at high temperature, and the weight of the concrete specimens decreased significantly compared with that before heating. In order to prevent water vapor from entering after heating, the specimen was wrapped by plastic bags. By measuring the mass change of the 
concrete specimens before and after high temperature, the burning loss curves of concrete with different strengths at different temperatures were obtained (Fig. 4). It was seen that the burning loss of general concrete basically presented three stages $[14,15]$. The first stage was a physical change process. When the temperature did not exceed $200{ }^{\circ} \mathrm{C}$, the main reason for the increase of the burning loss was the rapid evaporation of free water in the specimens. The second stage was a physical-chemical change process. When the temperature that the test specimen ensured was between 200 and $400{ }^{\circ} \mathrm{C}$, the growth rate of the loss of ignition was slower than that in the first stage. In this stage, the free water has been exhausted and the bound water was difficult to separate. The third stage was a chemical change process, in which the temperature of the specimen was between 400 and $800{ }^{\circ} \mathrm{C}$, and the loss of ignition was mainly caused by the decomposition of chemical components of concrete mortar and aggregate at high temperature, which was manifested as the dehydration of C-S-H gel crystal water and the dehydration of $\mathrm{Ca}(\mathrm{OH})_{2}$. Overall, the loss of ignition showed a law of increasing with the improvement of temperature.

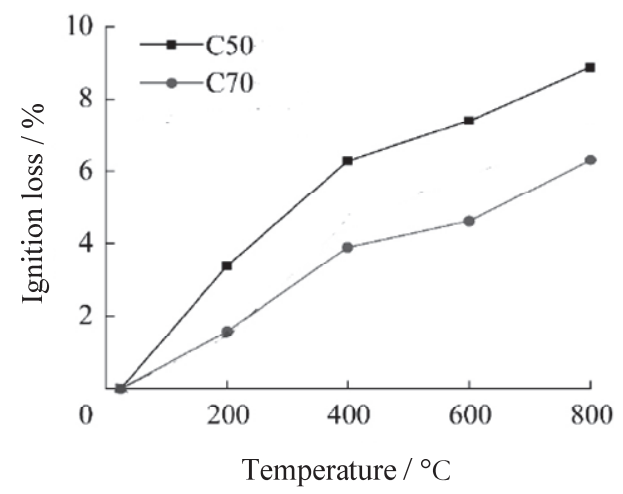

Figure 4: Relationship between ignition loss and elevated temperature.

For concrete of different strength grades, the physical and chemical effects were dominant respectively due to the large difference of water-cement ratio. For C50 concrete, the water-cement ratio was large, and the fast increasing stage of ignition loss was $0{ }^{\circ} \mathrm{C} \sim 400{ }^{\circ} \mathrm{C}$, in which free water loss was the main phenomenon. The loss caused by the physical effect was more obvious than that caused by the chemical effect. For $\mathrm{C} 70$ concrete, the water-cement ratio was moderate, the physical and chemical effects were equal, and the ignition loss remained stable as a whole. Overall, the loss of ignition presented a law of decreasing first and then increasing with the increase of the strength.

\section{Load-displacement Curve Of Specimens after High Temperature}

Complete load-displacement curves including load-crack mouth opening displacement (P-CMOD) curve and loaddeflection $(\mathrm{P}-\delta)$ curve can represent a series of important results, such as initial stiffness, ultimate bearing capacity, opening displacement corresponding to cracking load and instability load and hardening and softening characteristics, and the geometric shape of the curve can also reflect the toughness and brittleness of the material to a certain extent. Therefore, the full load-displacement curve plays a key role in the calculation of concrete fracture parameters.

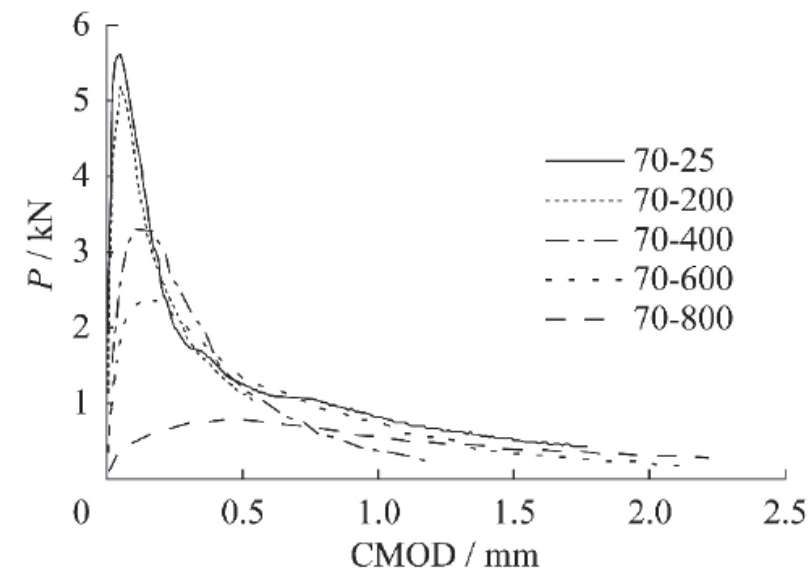

Figure 5: The curve of P-CMOD of the test specimens under different temperatures. 


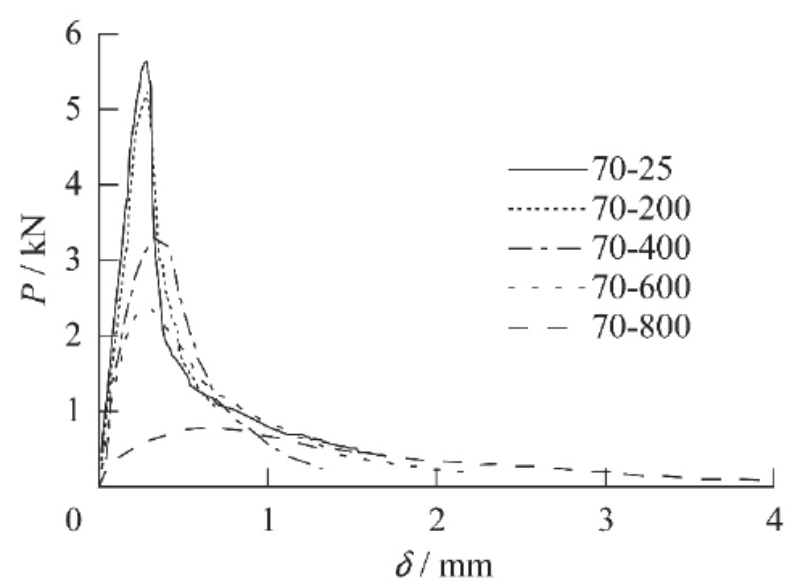

Figure 6: The curve of $\mathrm{P}-\delta$ of the test specimens under different temperatures.

Fig. 5 and 6 are the typical P-CMOD curve and P- $\delta$ curve of C70 concrete specimen at different temperatures. It was found that both types of curves showed a trend of shortening and fattening with the increase of temperature. The peak load decreased with the increase of temperature, and the corresponding critical CMOD and deflection increased.

Linear regression was made on a part of the ascending section of P-CMOD curve that was approximately straight line, and the coincidence degree between them was observed. The point where the curve began to deviate from the fitting straight line was found, and the corresponding load was the initial cracking load $\mathrm{P}_{\text {ini, }}$. Details are shown in Tab. 2.

\begin{tabular}{cccc}
\hline Temperature $/{ }^{\circ} \mathrm{C}$ & $\begin{array}{c}\mathrm{P}_{\mathrm{ini}, \mathrm{T}} / \mathrm{kN} \\
\mathrm{C} 70\end{array}$ & $\begin{array}{c}\mathrm{P}_{\max , \mathrm{T}} / \mathrm{kN} \\
\mathrm{C} 70\end{array}$ & $\begin{array}{c}\text { COMD corresponding } \\
\text { to } \mathrm{P}_{\max , \mathrm{T}} / \mathrm{mm} \\
\mathrm{C} 70\end{array}$ \\
25 & 3.80 & 5.78 & 46.88 \\
200 & 3.86 & 5.65 & 50.31 \\
400 & 2.33 & 3.66 & 79.13 \\
600 & 1.11 & 2.40 & 141.62 \\
800 & 0.25 & 0.73 & 368.36 \\
\hline
\end{tabular}

Table 2: Calculated results of fracture parameters (average values).

\section{Calculation of Fracture Toughness}

Fracture toughness of concrete is the ability of material to resist crack propagation. Initial fracture toughness $K_{I C}^{Q}$ represents the resistance to crack propagation when the crack is about to crack and the instability toughness $K_{I C}^{S}$ represents the resistance to external forces when the material is in critical instability state. Crack initial fracture toughness $K_{I C}^{Q}$ and instability toughness $K_{I C}^{S}$ can be calculated by the formula given in the Norm for Fracture Test of Hydraulic Concrete [16]:

$$
K_{I C}^{Q}=\frac{1.5\left(P_{\mathrm{int}, T}+\frac{\mathrm{mg}}{2} \times 10^{-2}\right) \times 10^{-3} S a_{0}^{1 / 2}}{t h^{2}} f\left(\alpha_{0}\right)
$$

where $f\left(\alpha_{0}\right)$ stands for a function related to the value of $a_{0} / h$, and its expression is:

$$
f\left(\alpha_{0}\right)=\frac{1.99-\alpha_{0}\left(1-\alpha_{0}\right)\left(2.15-3.93 \alpha_{0}+2.7 \alpha_{0}^{2}\right)}{\left(1+2 \alpha_{0}\right)\left(1-\alpha_{0}\right)^{3 / 2}}, \quad \alpha_{0}=\frac{a_{0}}{b}
$$




$$
K_{I C}^{S}=\frac{1.5\left(P_{\max , \mathrm{T}}+\frac{\mathrm{mg}}{2} \times 10^{-2}\right) \times 10^{-3} S a_{c}^{1 / 2}}{t h^{2}} f\left(\alpha_{c}\right)
$$

where $f\left(\alpha_{c}\right)$ is a function related to the value of $a_{c} / b$, and its expression is:

$$
f\left(\alpha_{c}\right)=\frac{1.99-\alpha_{c}\left(1-\alpha_{c}\right)\left(2.15-3.93 \alpha_{c}+2.7 \alpha_{c}^{2}\right)}{\left(1+2 \alpha_{c}\right)\left(1-\alpha_{c}\right)^{3 / 2}}, \quad \alpha_{c}=\frac{a_{c}}{b}
$$

where the calculation formula of $a_{c}$ is:

$$
a_{c}=\frac{2}{\pi}\left(b+h_{0}\right) \arctan \left(\frac{t E C M O D_{c}}{32.6 P_{\max , T}}-0.1135\right)^{1 / 2}-h_{0}
$$

where $P_{\text {ini, }}$ T stands for the initial crack load, $\mathrm{m}$ stands for the weight between the supports of the specimens, which is converted using the total mass of the specimens according to $\mathrm{S} / \mathrm{L}$ ratio, $\mathrm{g}$ is the acceleration of gravity, $9.81 \mathrm{~m} / \mathrm{s}^{2}$ here, $\mathrm{S}$ is the span between the two supports of the specimens, $a_{0}$ stands for the depth of the notch reserved at the middle and lower parts, $\mathrm{t}$ is the thickness of the specimens, $\mathrm{h}$ is the height of the specimens, $\mathrm{P}_{\max , \mathrm{T}}$ is the maximum load, $a_{c}$ stands for the effective crack length, $h_{0}$ stands for the thickness of the sheet steel plate at the notch, $\mathrm{E}$ is the elastic modulus, and $\mathrm{CMOD}_{\mathrm{c}}$ is the critical value of CMOD.

\section{Relationship between Fracture Toughness and Temperature}

Fig. 7a and b show the relationships of $K_{I C}^{Q}$ and $K_{I C}^{S}$ with temperature. It was seen from Fig. 7 that the general change trend of $K_{I C}^{Q}$ and $K_{I C}^{S}$ decreased with the increase of temperature.
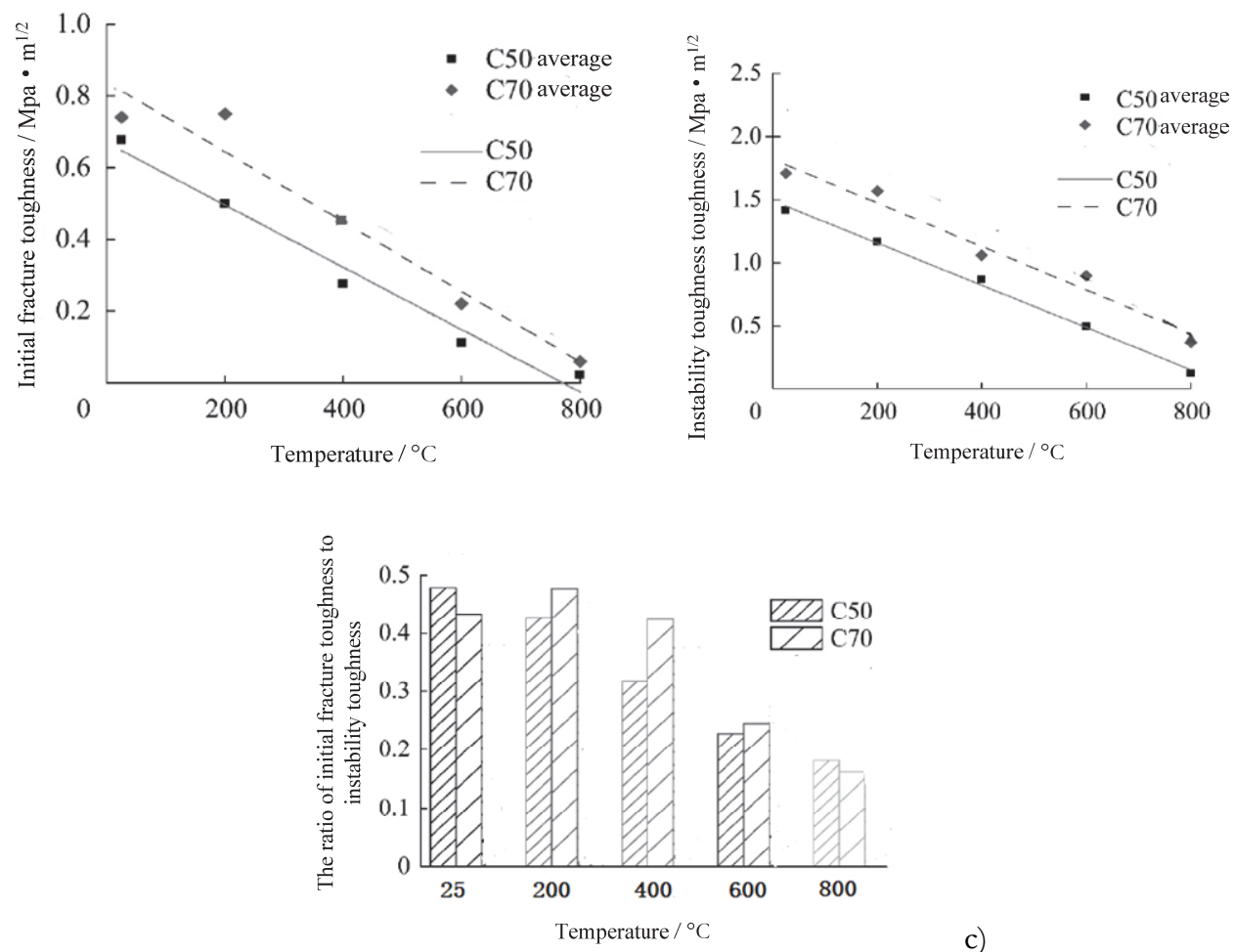

c)

Figure 7: Relationship between fracture toughness and elevated temperature. a) The change of initial fracture toughness with the maximum temperature; b) The change of instability toughness with the maximum temperature; c) The change of the ratio of initial fracture toughness to instability toughness with the maximum temperature. 
The relationship between the average values of $K_{I C}^{Q}$ and $K_{I C}^{S}$ of the concrete with different strength grades at different temperatures and temperature could be expressed by the following regression equations $\left(25^{\circ} \mathrm{C} \leq T_{m} \leq 800{ }^{\circ} \mathrm{C}\right)$.

$$
\begin{aligned}
& K_{I C}^{Q}=-0.001 T_{m}+0.8392, r=0.9532 \\
& K_{I C}^{S}=-0.0022 T_{m}+2.2086, r=0.9901
\end{aligned}
$$

As shown in Fig. 7(a), $K_{I C}^{Q}$ of the concrete of both strength grades decreased with the increase of temperature (C70 is abnormal at $200^{\circ} \mathrm{C}$ ). The slope of the regression fitting curve was 0.001 . The variation law of $K_{I C}^{S}$ with temperature was similar with $K_{I C}^{Q}$, as shown in Fig. 7(b).

As shown in Fig. 7(c), with the increase of the maximum temperature, the $K_{I C}^{Q} / K_{I C}^{S}$ of the concrete decreased (except $200^{\circ} \mathrm{C}$ ), indicating that $K_{I C}^{Q}$ decreased faster than $K_{I C}^{S}$ with the increase of the temperature, i.e., the sensitivity of $K_{I C}^{Q}$ to temperature was higher than that of $K_{I C}^{S}$.

\section{Calculation of Fracture Energy}

Fracture energy is defined as the energy consumed to form a unit fracture surface, usually expressed by GF [17]. The fracture energy of concrete can be directly obtained from the load-midspan displacement curve (i.e. P- $\delta$ curve) obtained from the fracture test. In the fracture test, the work on concrete specimens consists of two parts, i.e., the work done by the loading axis applied on the beam and the work done by the gravity of the beam itself. In the calculation, according to the principle of equal bending moment acting on the notch section, the beam weight was equivalent transformed into the concentrated external force $P_{w}$ acting on the loading point, $P_{w}=\frac{m g}{2}$. The deadweight equivalent force of the beam $P_{w}$ was applied to the beam together with the applied load $P_{a}$, so that the total load became $P_{w}+P_{a}$.

The displacement at the time of $P_{a}=0$ was denoted as $\delta_{0}$, the area under the total load-displacement curve could be divided into three parts, $W_{0}, W_{1}$ and $W_{2}$, as shown in Fig. 8. $W_{0}$ is the area under the curve of $P_{a}-\delta_{0}, W_{1}=P_{w} \delta_{0}$, and $W_{2}$ represents the area of the curve after point $\delta_{0}$. Reference [18] analyzed the value of $W_{2}$ and approximately considered $W_{1}=W_{2}$. Therefore, the total work done by the external force was:

$$
W=W_{0}+W_{1}+W_{2}=W_{0}+2 P_{m} \delta_{0}=W_{0}+m g \delta_{0}
$$

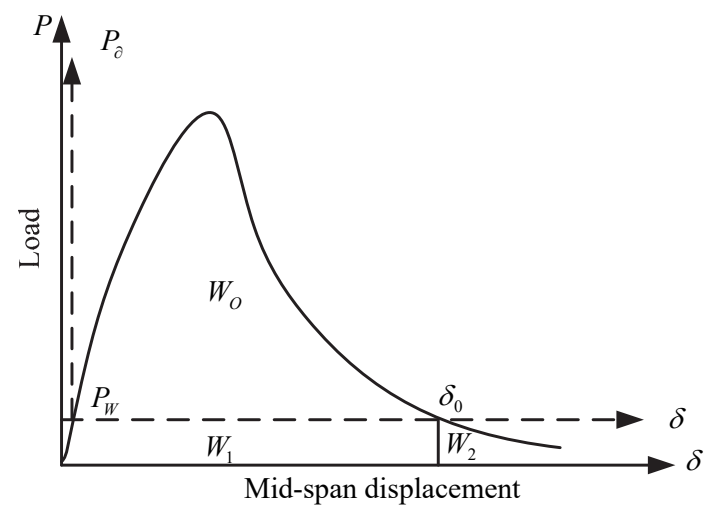

Figure 8: The diagram for the analysis of fracture energy calculated based on the load-midspan displacement.

It was assumed that all the work done by external forces flew into the fracture zone for fracture development, then the expression of fracture energy per unit area was: 


$$
G_{F}=\frac{W}{A_{\text {lig }}}=\frac{W_{0}+m g \delta_{0}}{t\left(b-a_{0}\right)}
$$

where $W_{0}$ stands for external work, $\delta_{0}$ stands for the CMPD when the specimen is damaged, $A_{\text {lig }}$ stands for the ligament area of the specimen, and $a_{0}$ stands for the height of the prefabricated crack of the specimen.

\section{Relationship between fracture energy and temperature}

The relationship between the average fracture energy of concrete with different strength grades at different temperatures and temperature can be expressed by the following regression equations.

$$
G_{F}=470.32 T^{-0.095}, r=0.8766
$$

It was noticed from Fig. 9 that for C70 concrete specimens, the fracture energy decreased sharply with temperature when the temperature was lower than $200^{\circ} \mathrm{C}$. When the temperature was higher than $200{ }^{\circ} \mathrm{C}$, temperature had little effect on fracture energy, the fracture energy showed a trend of slow decreasing, and the fracture energy was basically maintained at $297 \mathrm{~N} / \mathrm{m}$. The small variation of the fracture energy was because that the water-cement ratio of high-strength concrete was small, the proportion of cementitious material was large, and the crack development was relatively uniform. Overall, the fracture energy showed a law of decreasing rapidly first and then decreasing slowly with the development of temperature. The development law of fracture energy of concrete specimens with different strength grades with temperature was comprehensively analyzed. When the concrete strength was C50, the fracture energy increased first and then decreased. When the concrete strength was C70, the fracture energy decreased rapidly first and then slowly with the development of temperature.

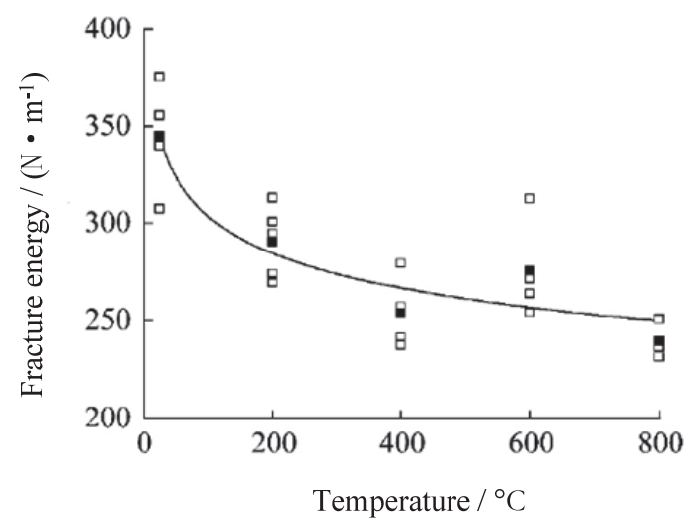

Figure 9: Relationship between fracture energy of concrete with different strength grades and elevated temperature

\section{CONCLUSIONS}

7 he fracture behavior of high strength concrete after high temperature was studied by the experiment of three-point bending beam with initial cracks. Comparative experiment was carried out by using C70 concrete. The load-midspan displacement curve and load-CMOD curve of concrete of different strength grades before and after high temperature were obtained. The fracture parameters such as initial cracking load, maximum load, critical value of CMOD, initial fracture toughness and instability toughness were calculated based on the load-CMOD. The fracture energy of the concrete was calculated based on the load-midspan displacement curve. The relationship of fracture parameters and fracture energy of concrete with temperature was analyzed and studied. The main contents and conclusions are as follows.

1. The ignition loss of the high-strength concrete decreased first and then increased with the increase of strength at high temperatures.

2. The initial fracture toughness $K_{I C}^{Q}$ and instability toughness $K_{I C}^{S}$ decreased with the increase of temperature, and the sensitivity of $K_{I C}^{Q}$ to temperature was higher than that of $K_{I C}^{S}$. 
3. Fracture energy $G_{F}$ decreased rapidly first and then slowly with the development of temperature.

\section{REFERENCES}

[1] Caggiano, A., Cremona, M., Faella C., Lima C. and Martinelli E. (2012). Fracture behavior of concrete beams reinforced with mixed long/short steel fibers, Construction \& Building Materials, 37(3), pp. 832-840.

DOI: 10.1016/j.conbuildmat.2012.07.060

[2] Akcay, B., Agar-Ozbek, A.S. and Bayramov, F. (2012). Interpretation of aggregate volume fraction effects on fracture behavior of concrete, Construction \& Building Materials, 28(1), pp. 437-443.

[3] Zhang, C., Yang, X. and Hu, G. (2018). Effect of randomness of interfacial properties on fracture behavior of concrete under uniaxial tension, Acta Mechanica Solida Sinica, 31(2), pp. 1-13.

[4] Arezoumandi, M. and Volz, J.S. (2013). Effect of fly ash replacement level on the fracture behavior of concrete, Frontiers of Structural and Civil Engineering, 7(4), pp. 411-418.

[5] Corr, D., Accardi, M., Graham-Brady, L. and Shah, SH. (2016). Digital image correlation analysis of interfacial debonding properties and fracture behavior in concrete, Engineering Fracture Mechanics, 74(1), pp. 109-121.

[6] Zhai, C., Wang, X. and Kong, J. (2017). A sophisticated simulation for the fracture behavior of concrete material using XFEM, Earthquake Engineering \& Engineering Vibration, 16(4), pp. 1-23.

[7] Simonin, F., Olagnon, C. and Maximilien, S. (2010). Room temperature quasi-brittle behaviour of an aluminous refractory concrete after firing, Journal of the European Ceramic Society, 22(2), pp. 165-172.

[8] Basamant, Z.P. and Becq-Giraudon, E. (2002). Statistical prediction of fracture parameters of concrete and implications for selection of test standard, Cement \& Concrete Research, 32(4), pp. 529-556.

[9] Gawin, D., Majorana, C.E. and Schrefler, B.A. (2015). Digital analysis of hygro thermal behaviour and damage of concrete at high temperature, International Journal for Digital \& Analytical Methods in Geomechanics, 4(1), pp. 37-74.

[10] Lu, Z.D., Yu, K.Q., Su, L., Lin, C.L. (2012) Residual fracture behaviors of concrete subjected to elevated temperatures, Journal of Building Materials, 15(6), pp. 836-840.

[11] Baker, G. (1996). The effect of exposure to elevated temperatures on the fracture energy of plain Concrete, RILEM Materials and Structures, 29(190), pp. 383-388.

[12] Menou, A., Mounajed, G., Boussa, H., Pineaud, A. and Carre, H. (2006). Residual fracture energy of cement paste, mortar and concrete subject to high temperature, Theoretical \& Applied Fracture Mechanics, 45(1), pp. 64-71.

[13] General Office of the National Development and Reform Commission. (2005). DL/T 5332-2005, Norm for fracture test of hydraulic concrete.

[14] Yan, L., Xing, Y.M. and Hao, Y.H. (2012). High temperature mechanical properties and microscopic analysis of hybrid fiber reinforced high performance concrete (HFHPC), Concrete, (1), pp. 24-28.

[15] Wang, B.S. and Li, Z. (2011). Experiment study on ascertaining the burning degree of the concrete components, Concrete, 27(2), pp. 162-167.

[16] Xu, S.L., Zhou, H.G., Gao, H.B. and Zhao, S.Y. (2006). An experimental study on double-K fracture parameters of concrete for dam construction with various grading aggregates, China Civil Engineering Journal, 39(11), pp. 50-62.

[17] Carloni, C., Santandrea, M. and Wendner, R. (2017). An investigation on the "width and size effect" in the evaluation of the fracture energy of concrete, Procedia Structural Integrity, 3, pp. 450-458.

[18] Swartz, S.E. and Yap, S.T. (1988) The influence of dead load on fracture energy measures using the RILEM method, Materials \& Structures, 21(6), pp. 410-415. 